\title{
Evaluation of antioxidant, antimicrobial activity and GC-MS analysis of Phlomis stewartii
}

\author{
Aroosa Farooq ${ }^{1}$, Samar Ali $^{1 *}$, Hamid Ullah ${ }^{2}$, Anwar Khan ${ }^{3}$, Nusrat \\ Jahan $^{3}$, Inayat Agha ${ }^{3}$ and Rasool Bakhsh Tareen ${ }^{4}$ \\ 1. Department of Chemistry, University of Balochistan, Quetta-Pakistan \\ 2. Department of Chemistry, Balochistan University of Information Technology, Engineering and Management \\ Sciences, Quetta-Pakistan \\ 3. Department of Biotechnology, Balochistan University of Information Technology, Engineering and Management \\ Sciences, Quetta-Pakistan \\ 4. Department of Botany, University of Balochistan, Quetta-Pakistan \\ *Corresponding author's email: samar121@gmail.com \\ Citation \\ Aroosa Farooq, Samar Ali, Hamid Ullah, Anwar Khan, Nusrat Jahan, Inayat Agha and Rasool Bakhsh Tareen. \\ Evaluation of antioxidant, antimicrobial activity and GC-MS analysis of Phlomis stewartii. Pure and Applied \\ Biology. Vol. 8, Issue 4, pp2420-2433. http://dx.doi.org/10.19045/bspab.2019.80187
}

\begin{tabular}{llll}
\hline \hline Received: 01/06/2019 & Revised: 31/08/2019 & Accepted: 02/09/2019 & Online First: 10/09/2019 \\
\hline \hline
\end{tabular}

\section{Abstract}

The myths of curing several ailments related to Phlomis in different countries since centuries brought our attention to unveil one of its potent specie. The main target was to explore biological activities of this species and to investigate presence of chemical constituents. The present work consists of preliminary phytochemical analysis, Gas Chromatography-Mass Spectrometry (GC-MS) analysis, antioxidant, antibacterial and antifungal activities of the Phlomis stewartii. Qualitative phytochemical analysis deduced the presence of the alkaloids, terpenes, coumarins, saponins, cardiac glycosides, phlobatannins, flavonoids, quinone, steroids and tannins. The quantitative analysis showed that the highest percentage of phenolic compounds were present in methanolic extract that was $48 \%$ while $42 \%$ in $n$-hexane fraction. The GC-MS analysis of $n$-hexane fraction revealed the presence of fourteen compounds. The antioxidant activity was tested via 2,2-diphenyl-1-picrylhydrazyl (DPPH) free radical with butylated hydroxytoluene (BHT) as standard antioxidant. The 50\% inhibitory concentration $\left(\mathrm{IC}_{50}\right)$ value of methanolic extract $(28.41 \pm 0.1)$ and n-hexane fraction $(37.16 \pm 0.007)$ whereas BHT $(16.83 \pm 0.03)$ were observed at same dilutions. The antibacterial activity of methanolic extract showed the inhibition zone (mm) against Bacillus subtilis $(14 \pm 0.18)$ and Staphylococcus aureus $(18 \pm 0.19)$ whereas $n$-hexane fraction inhibited former (12 \pm 0.18$)$ and later (13 \pm 0.21$)$. The antifungal activity resulted that $\mathrm{n}$-hexane fraction inhibited Rhizoctonia solani (40 \pm 0.94$)$, Alternaria alternate (25 \pm 0.81$)$ and Fusarium oxysporum $(12 \pm 0.67)$ whereas methanolic extract inhibited former (20 \pm 0.58$)$. The present work recommended that Phlomis stewartii may be further explored for testing biological activities after the isolation of individual components. The mixture and various combinations of these chemicals may hint actual potent agent which may be novel against vast varieties of microbes.

Keywords: Antibacterial; Antifungal; Antioxidant; Gas Chromatography-Mass Spectrometry; Phlomis stewartii; Phytochemical Analysis 


\section{Introduction}

Natural products either obtained from plants, animals or microbes are considered as important tools in medicinal field. A large number of natural products are used as starting material for drug development. Additionally, they are allowed to be marketed after several modifications to overcome side effects [1]. Natural products are categorized as primary and secondary metabolites, the later one are actually responsible for making them unique with respect to several characteristic benefits provided to different life forms $[2,3]$.

Medicinal plants are potent with respect to ailments cure and famous since ancient history. The plants are used for curing several ailments from simple fever to major diseases caused by pathogens in different parts of the world [4].The hidden chemistry for such curing potential lies in their phytochemicals which brings some uniqueness in plant and these substances are actually the center of attraction for several activities. These reported substances are up to 4500 and 350substances are completely characterized by using different techniques. These phytochemicals make the plant attractive by imparting color, flavor, and taste as well as protect them against foreign attack of living as well as non-living like exposure of ultraviolet rays, polluting agents etc. [5]. These substances when isolated and applied on other living organisms then they impart mixture of two behaviors that is detrimental as well as benign [6]. The most potent phytochemicals found in most of the plants are flavonoids, carotenoids, polyphenols, lignins, anthocyanins, indole-3-carbinol and glycosides [7].

Phlomis stewartii belongs to Lamiaceae family. It consists of rosy pink flowers; located in different areas of Pakistan especially in Suleiman and salt range. It is perennial plant with erect stems having 30-45 $\mathrm{cm}$ height. It consists of dense hairs and much branching at lower side. The leaves are thicktextured, aromatic, elliptic or narrow oblong, crenulate, acute at apex,length of calyx is $12 \mathrm{~mm}$. The corolla are rose to dusky pink with length of $2 \mathrm{~cm}$, tube exerted beyond calyx, calyx is surrounded by thin bracts nearly 18 in number $[8,9]$.

In present work, Phlomis stewartii was studied for the GC-MS analysis of n-hexane fraction and preliminary phytochemical analysis of the plant along with evaluation of antibacterial, antifungal and antioxidant activities.

\section{Materials and methods Plant material}

The plant sample was collected from Ziarat, Balochistan in the month of April, 2017 and identified by Dr. Rasool Bakhsh Tareen, Professor Department of Botany, University of Balochistan, and Quetta. The plant $(7 \mathrm{~kg}$ ) was extracted thrice with methanol in order to obtain maximum chemical constituents in the extract [10].The obtained methanolic extract was fractionated into n-hexane and ethyl acetate fractions.

\section{GC-MS analysis}

Gas Chromatography (GC) was used to determine the retention time and Mass spectrometry (MS) was used to determine the molecular ion peak and fragment ion peaks of compounds. The column $(30 \mathrm{~m} \times 250 \mu \mathrm{m} \times 0.25 \mu \mathrm{m})$ was packed with $5 \%$ phenyl methyl siloxane as stationary phase. The helium gas used as mobile phase which allowed the sample to move across the column. The oven temperature was initially set at $50{ }^{\circ} \mathrm{C}$ for at least 3 minutes and then it was increased from $10-180{ }^{\circ} \mathrm{C} / 15$ minutes. In the second step, temperature was raised up to a maximum of $300{ }^{0} \mathrm{C}$, the maximum temperature and pressure of oven recorded as $360{ }^{0} \mathrm{C}$ and $9.05 \mathrm{psi}$ respectively. The complete run up time was 68 minutes [11] 
and the mass spectra thus obtained were matched with already available data in Replib and Mainlib [12].The electron impact (EI) used as a source for ionization at $250{ }^{\circ} \mathrm{C}$.

\section{Qualitative analysis}

The methanolic extract and n-hexane fraction were evaluated for the presence of alkaloids, terpenes, coumarins, saponins, cardiac glycosides, phlobatannins, flavonoids, quinone, steroids and tannins by adopting methods described in previous reported literature [12]. The test methodsare included in (Table 1).

Table 1. Qualitative analysis of Methanolic extract and n-hexane fraction

\begin{tabular}{|c|c|c|}
\hline Compounds type & Methanolic extract & n- Hexane fraction \\
\hline Alkaloids & Dark red color appeared & Dark red color appeared \\
\hline Cardiac Glycosides & $\begin{array}{l}\text { Two rings formed, lower one } \\
\text { reddish brown while upper one } \\
\text { was bluish green }\end{array}$ & $\begin{array}{l}\text { Two rings formed, lower one } \\
\text { reddish brown while upper one was } \\
\text { bluish green }\end{array}$ \\
\hline Coumarin & Light Yellow colored & Light Yellow colored \\
\hline Flavonoids & $\begin{array}{l}\text { Yellow color appeared which was } \\
\text { changed later due to introduction } \\
\text { of } \mathrm{HCl}\end{array}$ & $\begin{array}{l}\text { Yellow color appeared which was } \\
\text { later disappeared as soon as dil. } \\
\text { HCl was introduced }\end{array}$ \\
\hline Phlobatannins & No change & No change \\
\hline Quinone & Intense red color appeared & Medium red color appeared \\
\hline Saponins & Foam appeared & Foams appeared \\
\hline Steroids & $\begin{array}{c}\text { Red layer at lower side of test } \\
\text { tube appeared }\end{array}$ & $\begin{array}{c}\text { Red layer at lower side of test tube } \\
\text { appeared }\end{array}$ \\
\hline Tannins & Light greenish ppt. appeared & Light greenish ppt. appeared \\
\hline Terpenoids & Reddish ring appeared & Medium reddish rings appeared \\
\hline
\end{tabular}

\section{Quantitative analysis}

The quantitative analysis of n-hexane and methanolic extract were determined for total alkaloid contents, total phenolic contents, total saponins and total flavonoids contents. The methodology thus adopted was already reported $[13,14]$.

\section{Antioxidant activity}

The n-hexane fraction and methanolic extract were evaluated for antioxidant activity. The 2,2-diphenyl-1-picrylhydrazyl(DPPH) was used as free radical while BHT as a standard antioxidant. The plant sample and DPPH were dissolved in methanol, so methanol was used as reference. The DPPH (0.004 g) was dissolved in $100 \mathrm{~mL}$ of methanol. The dilutions $(250,125,50,10) \mathrm{mg} / \mathrm{L}$ were prepared from the $5 \mathrm{mg} / \mathrm{L}$ stock solution for plant sample and BHT standard. All the prepared samples were kept in dark for a period of 20-25 minutes in dark for providing them the time to complete the reaction. The UV Spectrophotometer (Shimadzu, Japan) was used and all the prepared dilutions absorbance measured at $517 \mathrm{~nm}$. The decrease in absorbance confirmed the scavenging activity of sample $[10,15]$. The following formula was used to assayed antioxidant activity of plant sample.

\%age scavenging of DPPH

= Abs control- Abs sample/Abs control

The effectiveness of sample was further checked by $\mathrm{IC}_{50}$ value obtained from slope by using formula as;

IC50 $=50-\mathrm{b} / \mathrm{a}$ ( $\mathrm{a}$ and $\mathrm{b}$ are obtained from slope)

\section{Antifungal activity}

The antifungal activity of sample was tested by using disc diffusion method and agar well diffusion method. The Potato Dextrose Agar (PDA) was used as nutrient and fungi were 
Alternaria alternate, Rhizoctonia solani and Fusarium oxysporum.

\section{Disc diffusion method}

The fungi were placed at center of the discs and samples applied at peripheral region. The diameter of disc was $6 \mathrm{~mm}$ and allowed for incubation for 3 days at $37{ }^{\circ} \mathrm{C}$ in dark. This method was used to assess the samples on the basis of qualitative analysis [16].

\section{Agar well diffusion method}

This method adopted for the quantitative analysis of the plant samples against fungi. The different concentrations of sample were prepared by dissolving in Dimethyl sulfoxide (DSO). The concentrations ranging from 20$100 \mu \mathrm{L}$ were prepared and then added each into the well. The fungi inoculum was allowed to spread on dish and well bored to a depth of $8 \mathrm{~mm}$. The samples kept for 3-4 hours in inverted position and after that placed them in incubator for 48-72 hours at $37{ }^{\circ} \mathrm{C}$. The mycotic inhibition was determined by following formula; \%age mycelial Inhibition $=\left[\left(\mathrm{d}_{c}-\mathrm{d}_{t}\right) / \mathrm{d}_{c}\right] \times 100$ $\mathrm{d}_{c}=$ Diameter of fungal growth in control $\mathrm{d}_{t}=$ Diameter of fungal growth under test The procedure repeated in triplicate in order to confirm the authenticity and liability of work.

\section{Antibacterial activity}

The methanolic extract and n-hexane fraction of the plant were subjected for antibacterial activity. The two gram positive bacteria, Escherichia coli and Shigella dysenteriae and two gram negative bacteria Bacillus subtilis and Staphylococcus aureus were selected to analyze the antibacterial activity. Macchonkey agar (MA) and Eosin methylene blue (EMB) were used as selective media to confirm the presence of gram negative bacteria whereas Mannitol Salt Agar (MSA) used as selective media to test the presence of gram positive bacteria. After the initial screening, nutrient agar, Muellar Hinton Agar (MHA) was prepared for all the four bacteria, and samples incubated for 24 hours at $24-28{ }^{\circ} \mathrm{C}$.

\section{Disc diffusion method}

A fresh colony of each bacterium was taken and dissolved in saline water to retain the cell wall of bacteria. They were compared with McFarland standard 0.05 and the colonies transparency of bacteria should be match able with it [17]. The stock solution of sample was diluted as $0.1,0.12,0.14,0.16$ and $0.18 \mathrm{~g} / \mu \mathrm{L}$ and used to determine minimum inhibitory concentration (MIC). The antibiotic Novobiocin acted as positive control while DMSO used as negative control. The conclusion was drawn by comparing the samples with positive control.

\section{Results and discussion GC-MS analysis}

The n-hexane fraction of Phlomis stewartii was investigated via GC-MS technique. The list of compounds, their molecular formula (MF), molecular weight (MW), and retention time (RT), area sum \% peaks are incorporated in (Table 2). The GC chromatogram showed relative concentration of each compound verses retention time. The chromatograms included as (Figure $1 \& 2$ ). The mass spectra of most abundant compounds are added as (Figure 3-6).

The data obtained from the present work showed the presence of 14 compounds including phytol, steroids, eicosanoic acid, Linoleic acid, pregnane, stigmasterol, $\beta$ Sitosterol, 9,12-octadecadioic acid, hexadecadioic acid etc. Among them, stigmasterol, $\beta$-sitosterol and phytol have antioxidant potential. The ester based compounds have the potential of scavenging free radicals [18]. The long chain fatty acids including eicosanoic acid, linoleic acid etc. are potent agent for antibacterial activities. The presence of above compounds in $\mathrm{n}$ hexane fraction revealed its medicinal importance [19-21]. 
Table 2. Chemical Constituents present in n-hexane fraction obtained via GC-MS Analysis

\begin{tabular}{|c|c|c|c|c|c|}
\hline $\begin{array}{l}\text { Peak } \\
\text { No. }\end{array}$ & $\begin{array}{c}\text { RT } \\
(\mathbf{m i n})\end{array}$ & Name of compound & $\begin{array}{c}\text { Mol. } \\
\text { Formula }\end{array}$ & $\begin{array}{c}\text { Mol. } \\
\text { Weight }\end{array}$ & $\begin{array}{c}\text { Area } \\
\text { sum \% }\end{array}$ \\
\hline 1 & 32.32 & 2-Pentadecanone, 6,10,14-trimethyl & $\mathrm{C}_{18} \mathrm{H}_{36} \mathrm{O}$ & 268 & 1.05 \\
\hline 2 & 35.011 & Hexadecanoicacid,methyl ester & $\mathrm{C}_{17} \mathrm{H}_{34} \mathrm{O}_{2}$ & 270 & 4.69 \\
\hline 3 & 35.895 & n-Hexadecanoic acid & $\mathrm{C}_{16} \mathrm{H}_{32} \mathrm{O}$ & 256 & 18.23 \\
\hline 4 & 38.328 & $\begin{array}{l}\text { 9,12-Octadecadienoic acid, methyl ester (E, } \\
\text { E) }\end{array}$ & $\mathrm{C}_{19} \mathrm{H}_{34} \mathrm{O}_{2}$ & 294 & 1.07 \\
\hline 5 & 38.61 & Phytol & $\mathrm{C}_{20} \mathrm{H}_{40} \mathrm{O}$ & 296 & 5.82 \\
\hline 6 & 38.76 & Octadecanoic acid, methyl ester & $\mathrm{C}_{19} \mathrm{H}_{38} \mathrm{O}_{2}$ & 298 & 1.39 \\
\hline 7 & 38.909 & 9,12-octadecadienoic acid, methyl ester $(\mathrm{Z}, \mathrm{Z})$ & $\mathrm{C}_{18} \mathrm{H}_{32} \mathrm{O}_{2}$ & 280 & 9.37 \\
\hline 8 & 39.02 & $\begin{array}{l}\text { 9,12,15-Octadecatrienoic acid, }(\mathrm{Z}, \mathrm{Z}, \mathrm{Z}) \\
\text { (Linoleic acid) }\end{array}$ & $\mathrm{C}_{18} \mathrm{H}_{30} \mathrm{O}_{2}$ & 278 & 9.67 \\
\hline 9 & 39.248 & Octadecanoic acid (Stearic acid) & $\mathrm{C}_{18} \mathrm{H}_{36} \mathrm{O}_{2}$ & 284 & 4.15 \\
\hline 10 & 41.547 & Eicosanoic acid & $\mathrm{C}_{20} \mathrm{H}_{40} \mathrm{O}_{2}$ & 312 & 0.55 \\
\hline 11 & 43.407 & 1,2-Benzenedicarboxylic acid, dissooctyl ester & $\mathrm{C}_{24} \mathrm{H}_{38} \mathrm{O}_{4}$ & 390 & 39.53 \\
\hline 12 & 55.061 & $\begin{array}{c}\text { Pregnane -3,11,20,21-tetrol,cyclic20,21- } \\
\text { (butylboronate), }(3 \alpha, 5 \beta, 11 \beta, 20 \mathrm{R})\end{array}$ & $\mathrm{C}_{25} \mathrm{H}_{43} \mathrm{BO}_{4}$ & 418 & 0.3 \\
\hline 13 & 55.92 & Stigmasterol & $\mathrm{C}_{29} \mathrm{H}_{48} \mathrm{O}$ & 412 & 0.46 \\
\hline 14 & 57.709 & $\beta$-Sitosterol & $\mathrm{C}_{29} \mathrm{H}_{50} \mathrm{O}$ & 414 & 3.72 \\
\hline
\end{tabular}

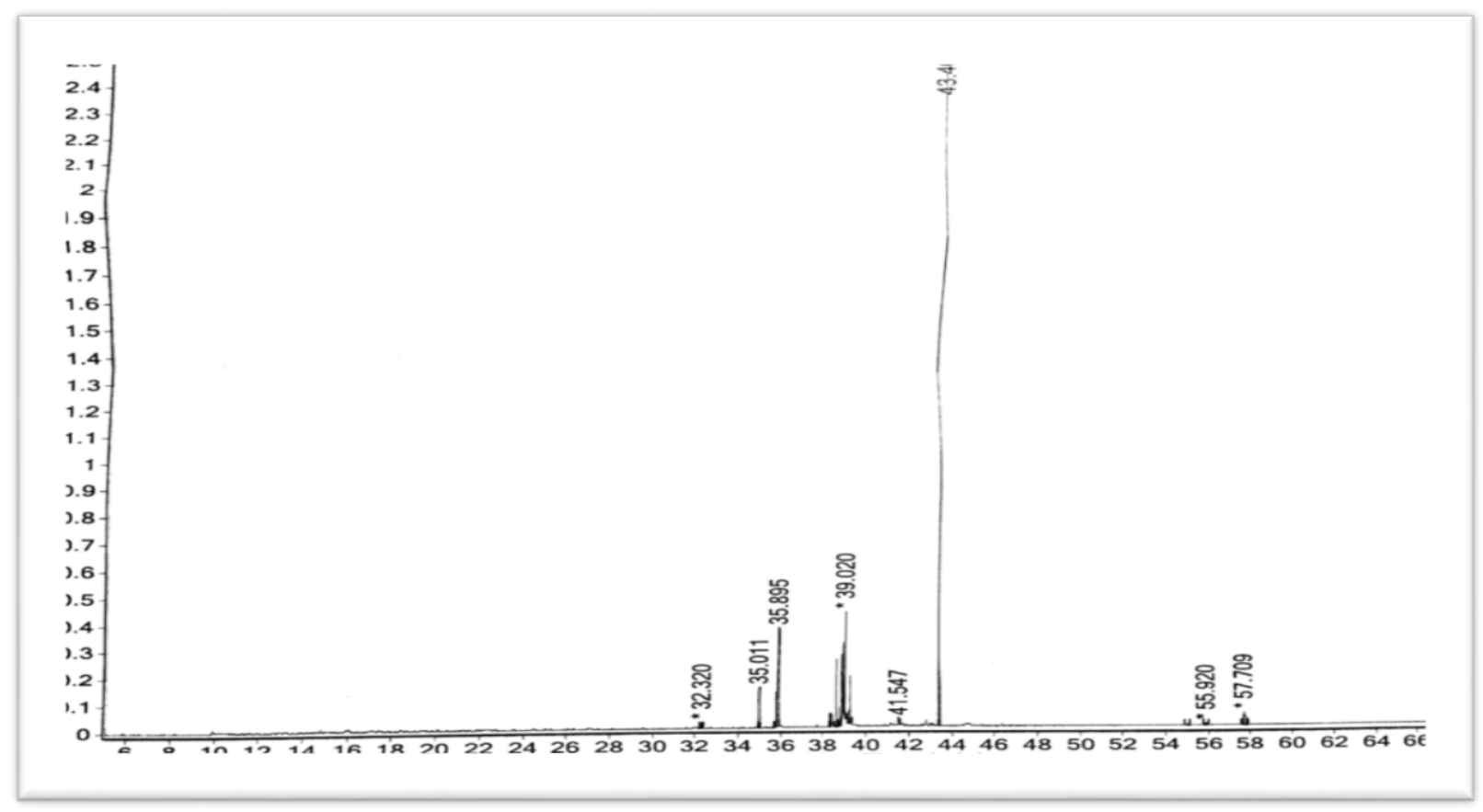

Figure 1. Chromatogram of n- hexane fraction of Phlomis stewartii 
Farooq et al.

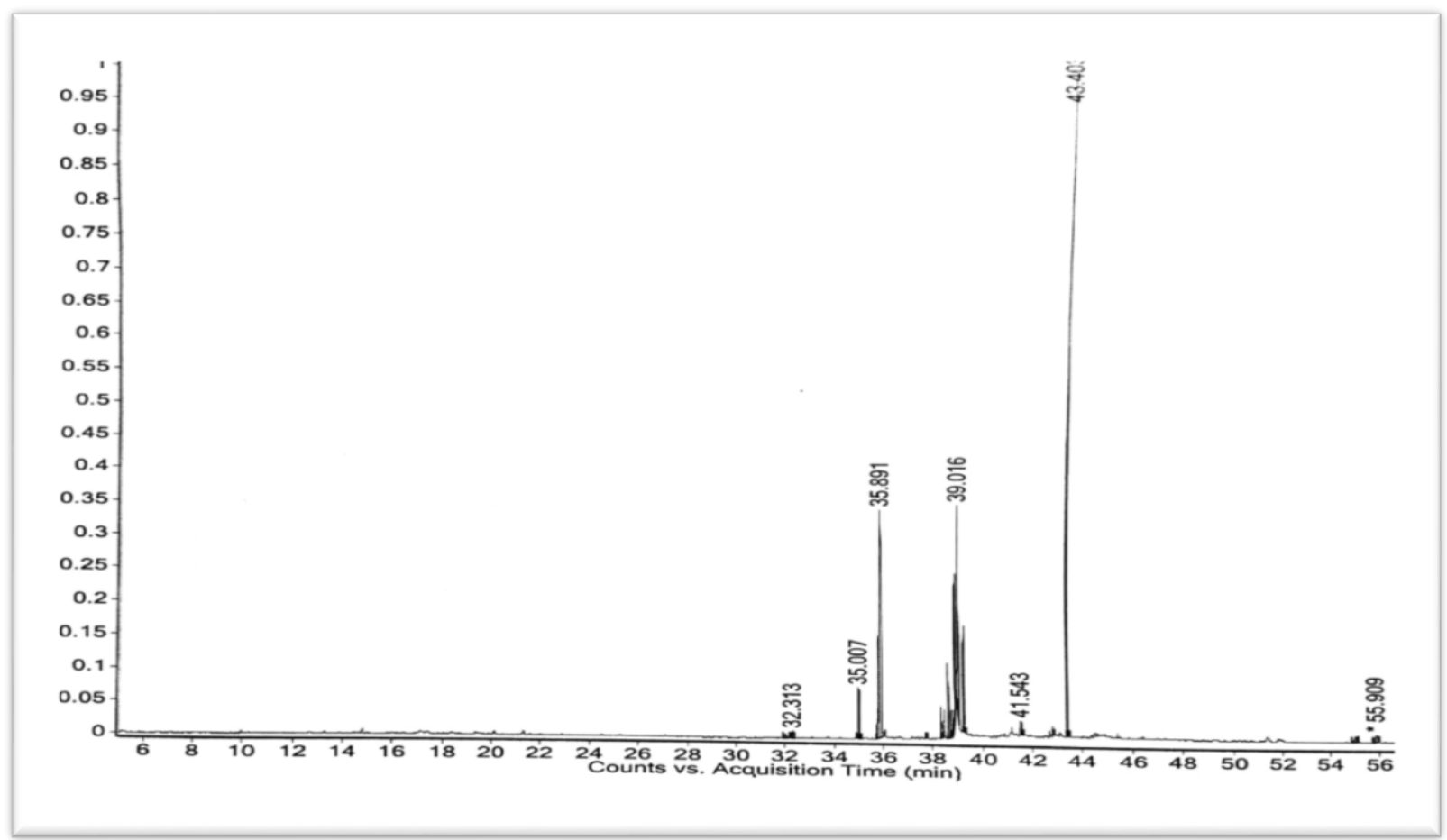

Figure 2. Chromatogram obtained from n-hexane fraction

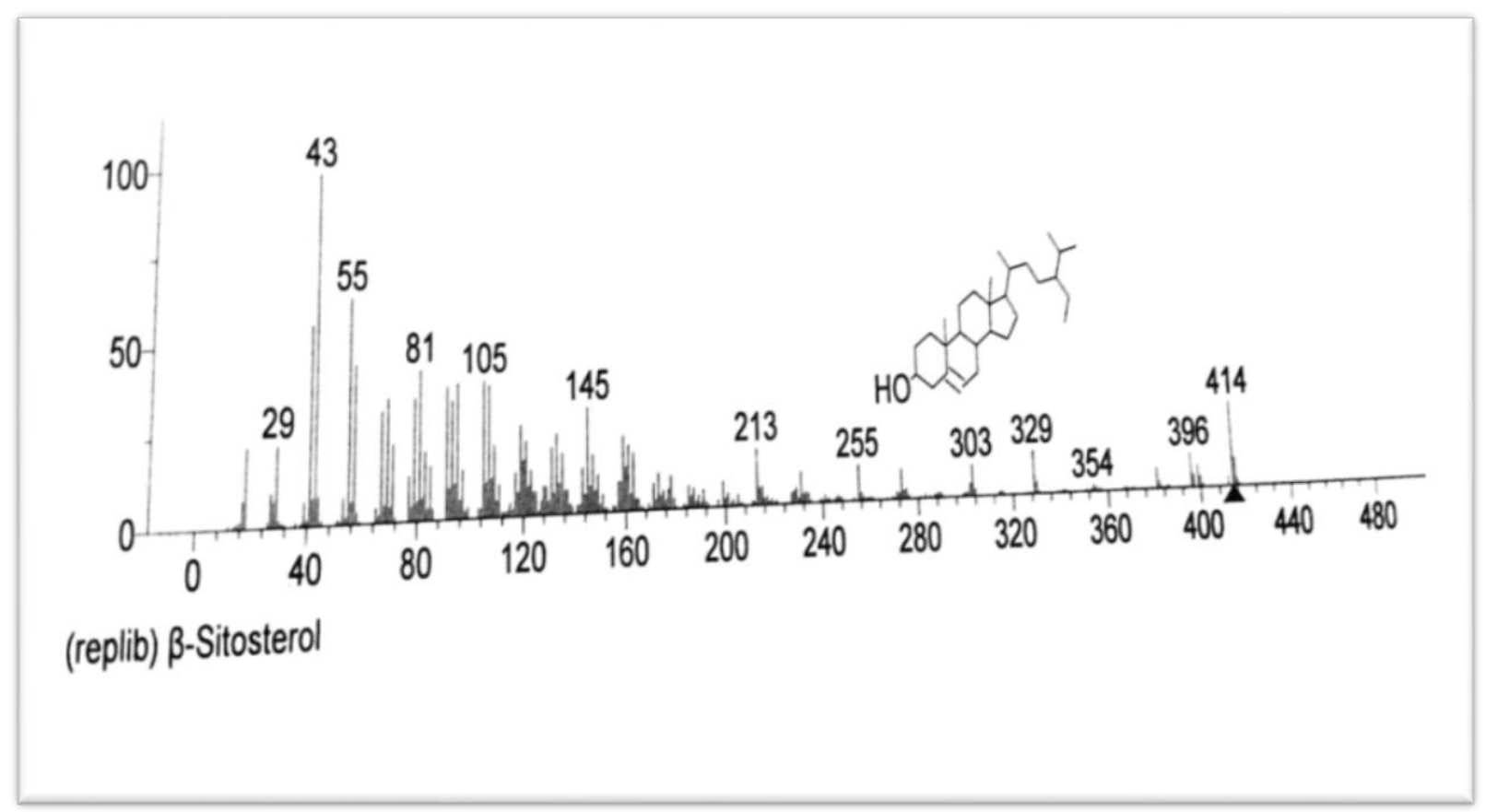

Figure 3. Mass Spectrum of $\beta$-Sitosterol 


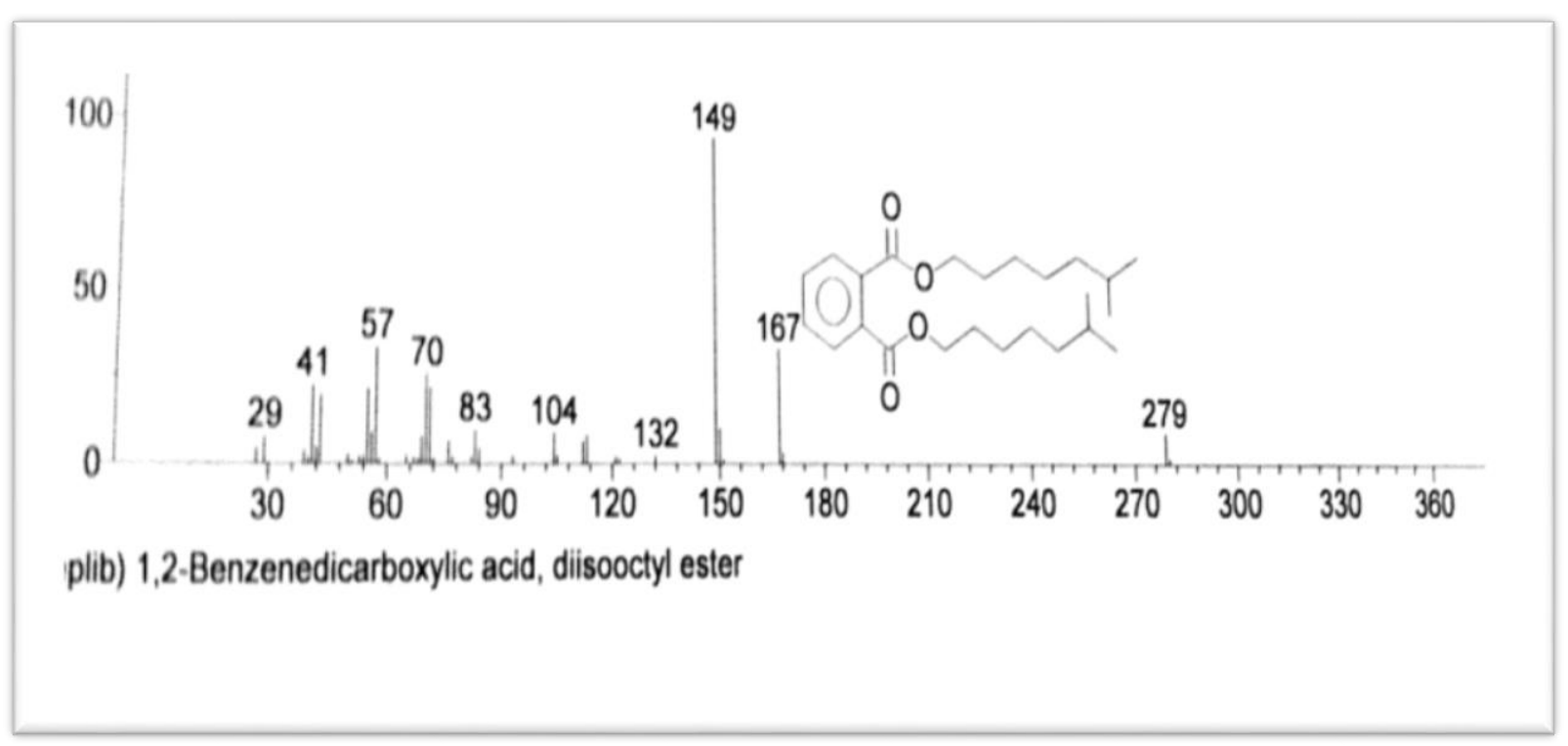

Figure 4. Mass Spectrum of 1,2-Benzenedicarboxylic acid, disoctyl ester

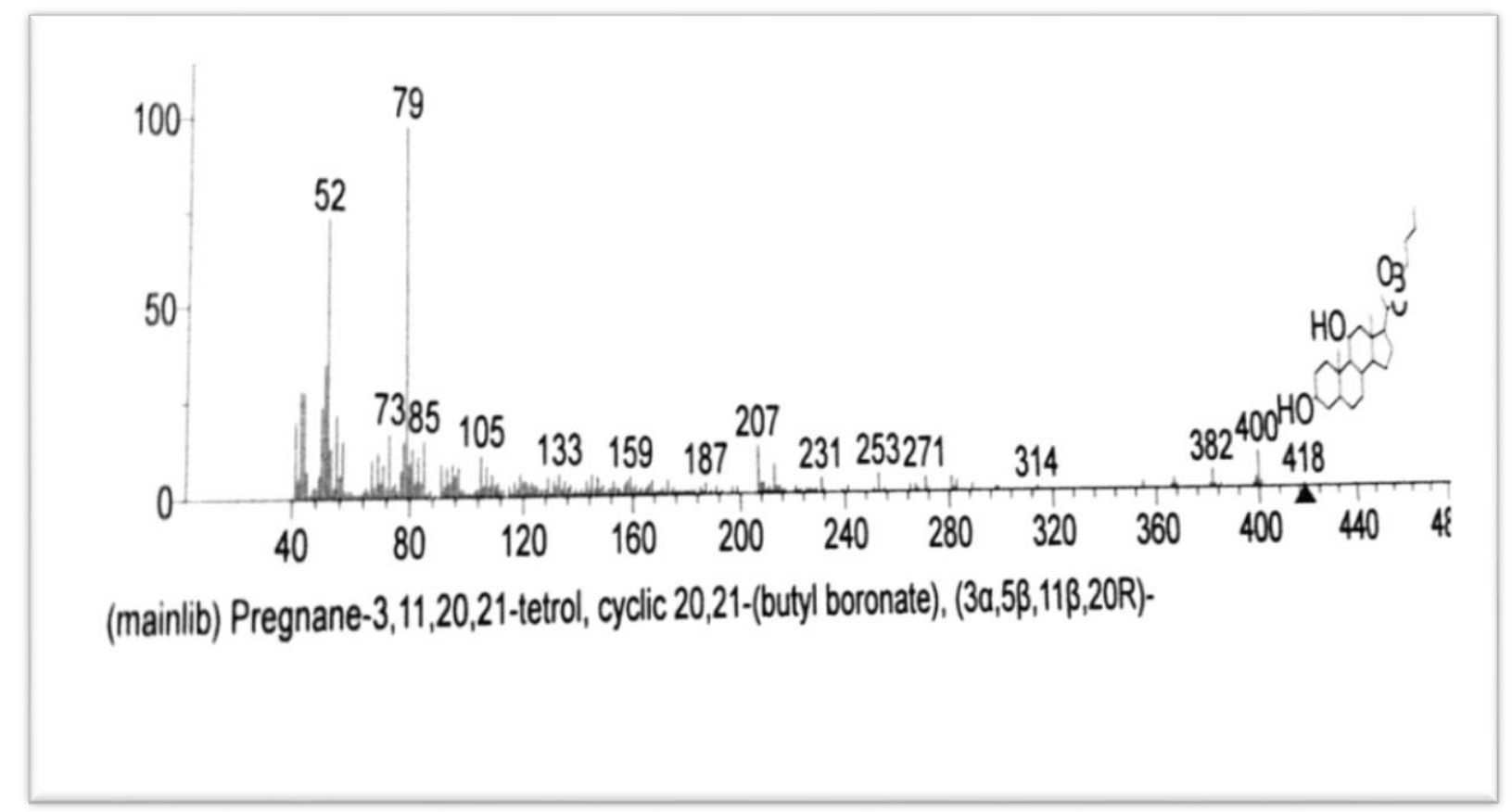

Figure 5. Mass Spectrum of Pregnane-3,11,20,21-tetrol, cyclic 20,21-(butyl boronate), (3a, $5 \beta, 11 \beta, 20 R)$ 


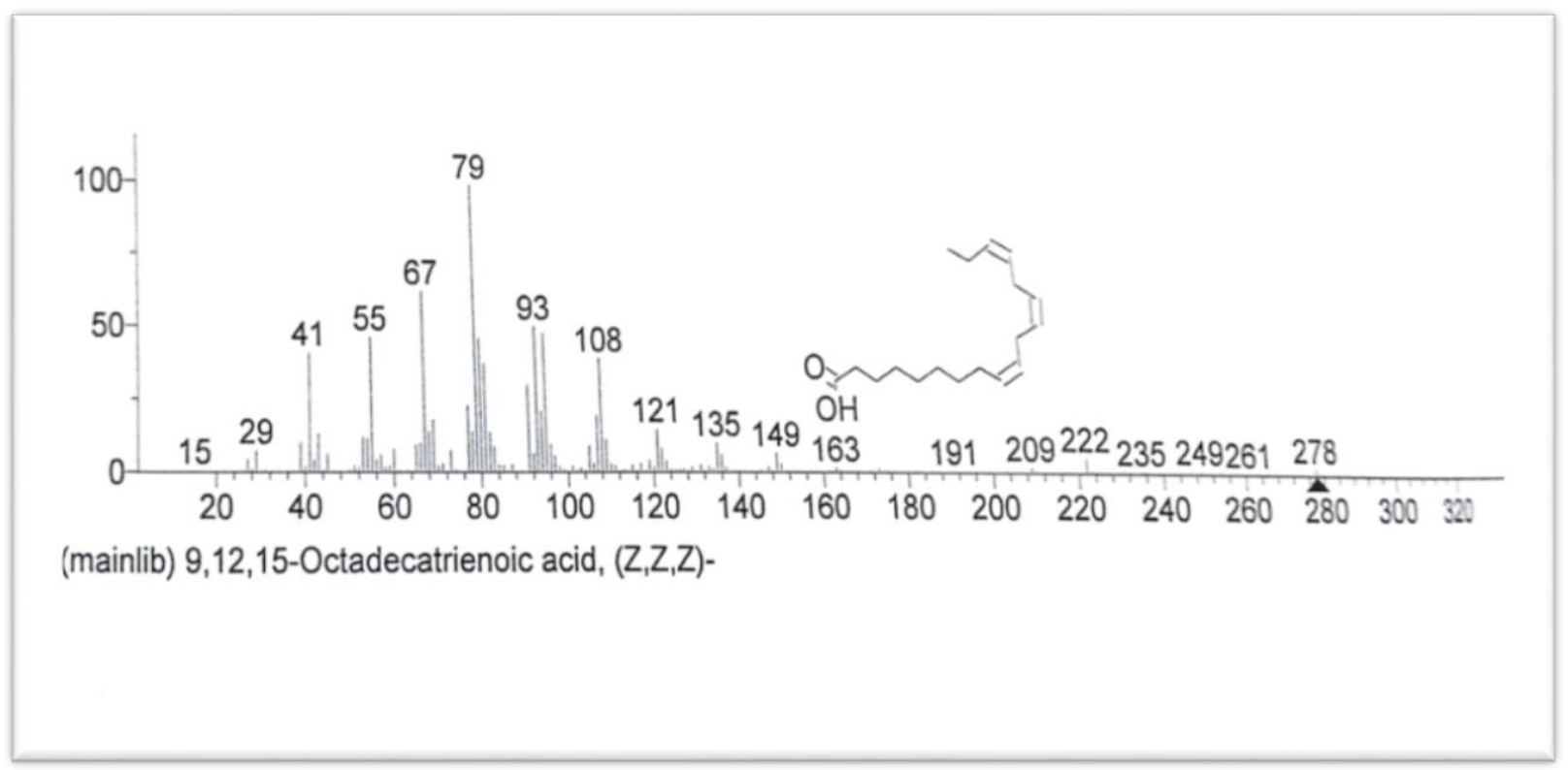

Figure 6. Mass Spectrum of Linoleic acid

\section{Qualitative analysis}

The methanolic extract and n-hexane fraction were assessed for the qualitative analysis and it was observed that n-hexane fraction contained the largest amount of alkaloids while terpenoids, cardiac glycosides, steroids, flavonoids were in moderate amount. The methanolic extract indicated the presence of alkaloids, cardiac glycosides, coumarins, flavonoids, quinones, saponins, steroids, tannins, terpenoids. These results revealed the presence of such important phytochemicals which were found to be helpful in imparting antimicrobial, antioxidant, anti-analgesic, antiinflammatory actions [22-24]. The said chemical constituents are reported as active agents for antioxidant and antimicrobial activities [16, 25, 26]. The results are included in (Table 3).

\section{Quantitative analysis}

The methanolic extract and n-hexane fraction were evaluated for quantitative analysis. It was revealed that highest \%age of phenolic compounds were present in methanolic extract that was $48 \%$ while $42 \%$ in n-hexane fraction. The results are incorporated in (Table 4).

The compounds present in methanolic extract and n-hexane fraction are reportedly biologically important such as flavonoids are antioxidant and antiviral agents [27].

\section{Antioxidant activity}

The antioxidant activity of Phlomis stewartii was tested and IC50 obtained from different dilutions showed the potency of sample as an antioxidant. The decoloration of DPPH from purple color indicated the scavenging of it by sample and BHT. The results showed that methanolic fraction $(28.42 \pm 0.1)$ is more potent antioxidant than n-hexane fraction (37.16 \pm 0.007$)$. The results are shown in (Table 5).

The DPPH scavenging effect was calculated by absorbance of control and sample difference, the samples were tested in triplicate and then $\mathrm{IC}_{50}$ was obtained from the DPPH scavenging activity graphs at different dilutions. The graphical representation is included in (Figure $7 \& 8$ ). The scavenging activity indicating the presence of some antioxidant in plant sample such as 
polyphenols and quinines can be reason for antioxidant activity.

The antioxidant activity was found to be dependent upon hydrophilic and hydrophobic nature of components, larger electron donor groups like - $\mathrm{OH}$ in phenylpropanoids favours more activity [10]. BHT has such phenolic group which resembled with phenolic skeleton of antioxidants present in plants. The stable free radical (DPPH) was chosen and absorbance was measured at $517 \mathrm{~nm}$ and reduction in absorbance was observed due to engulfing of free radicals. It was due to provision of hydrogen by antioxidant [15]. Flavonoids and several glycosides which contain hydroxyl groups are much effective agents of such activities [26].

\section{Antifungal activity}

The n-hexane and methanolic extract were assessed for antifungal activity and Alternaria alternate, Rhizoctonia solani and Fusarium oxysporum were used as fungal agents. The potency of $n$-hexane fraction and methanolic extract was tested by means of qualitative as well as quantitative analysis. The results revealed that $\mathrm{n}$-hexane fraction inhibited the $R$. solani $(40 \pm 0.94)$, A. alternate $(25 \pm 0.81)$ and $F$. oxysporum $(12 \pm 0.67)$ whereas methanolic extract inhibited only $A$. alternate $(20 \pm 0.58)$. The results are shown in (Table 6 \& Figure 9).
The use of medicinal plants as antifungal agents is in practice since ancient times and their use in development of drugs against fungal pathogens has minimized the chances of adverse side effects on human health. The demand for appropriate anti-fungal agents also get importance after finding of adverse action of many fungi, especially in destroying the quality, quantity, mortality and shelf life of useful crops. The discovery of new drugs for inhibiting fungi is actually a new aspect of human pathology [28, 29].

\section{Antibacterial activity}

In present study, methanolic extract and nhexane fraction were also assayed for antibacterial activity against gram negative bacteria (E. coli, B. Subtilus) and gram positive bacteria ( $S$. aureus \& S. dysenteriae). It was revealed n-hexane fraction showed MIC against $S$. aureus $(13 \pm 0.21)$ and $B$. subtilus $(12 \pm 0.18)$ while methanolic extract was more active against $B$. subtilus $(14 \pm 0.18)$ and $S$. aureus (18 \pm 0.19$)$. The results are shown in (Table 7,8 \& Figure 10). The previous findings related to this activity supported present results, antibacterial activity depends upon synergism of components in a mixture rather than a single isolated compounds, while for some bacteria one compound can be effective than extract or fraction [16].

Table 1. Qualitative analysis for checking strength of components in n-hexane fraction and methanolic extract

\begin{tabular}{|c|c|c|}
\hline Compounds type & Methanolic extract & n- Hexane fraction \\
\hline Alkaloids & +++ & +++ \\
\hline Cardiac Glycosides & ++ & ++ \\
\hline Coumarin & + & + \\
\hline Flavonoids & ++ & ++ \\
\hline Phlobatannins & - & - \\
\hline Quinone & +++ & ++ \\
\hline Saponins & ++ & + \\
\hline Steroids & ++ & ++ \\
\hline Tannins & + & + \\
\hline Terpenoids & +++ & ++ \\
\hline
\end{tabular}

+++ indicated the more abundance of respective phytochemicals, while ++ revealed moderate level of phytochemicals and + showed the lowest concentration of that phytochemical in particular sample. - indicated the absence of that substance in sample 
Table 2. Phytochemical contents in methanolic extract and $\mathbf{n}$-hexane fraction

\begin{tabular}{|c|c|c|}
\hline Phytochemical contents & Methanolic extract & n-Hexane fraction \\
\hline Total Alkaloid contents & $34 \%$ & $22 \%$ \\
\hline Total Flavonoid contents & $25 \%$ & $26 \%$ \\
\hline Total Phenolic contents & $48 \%$ & $42 \%$ \\
\hline Total saponins & $5 \%$ & $1 \%$ \\
\hline
\end{tabular}

Table 5. Antioxidant activity of Phlomis stewartii

\begin{tabular}{|c|c|c|c|}
\hline Sample & $\begin{array}{c}\text { Concentration } \\
(\mu \mathrm{g} / \mathrm{mL})\end{array}$ & $\begin{array}{c}\text { \%age scavenging of DPPH } \\
\text { Radical } \pm \text { SEM }\end{array}$ & $\begin{array}{c}\mathrm{IC}_{50} \text { of DPPH } \\
\operatorname{assay}(\mu \mathrm{g} / \mathrm{mL}) \pm \mathrm{SEM}\end{array}$ \\
\hline \multirow{5}{*}{$\begin{array}{c}\text { Methanolic } \\
\text { Extract }\end{array}$} & 250 & $90.8 \pm 0.03$ & \multirow{5}{*}{$28.42 \pm 0.1$} \\
\hline & 120 & $88.5 \pm 0.07$ & \\
\hline & 60 & $77.8 \pm 0.03$ & \\
\hline & 30 & $45.8 \pm 0.08$ & \\
\hline & 15 & $25.3 \pm 0.07$ & \\
\hline \multirow{5}{*}{ n-hexane fraction } & 250 & $88.2 \pm 0.05$ & \multirow{5}{*}{$37.16 \pm 0.007$} \\
\hline & 120 & $75.5 \pm 0.04$ & \\
\hline & 60 & $60.2 \pm 0.04$ & \\
\hline & 30 & $45.3 \pm 0.04$ & \\
\hline & 15 & $39.3 \pm 0.07$ & \\
\hline \multirow{5}{*}{ BHT } & 250 & $96.2 \pm 0.05$ & \multirow{5}{*}{$16.83 \pm 0.03$} \\
\hline & 120 & $82.9 \pm 0.03$ & \\
\hline & 60 & $69.5 \pm 0.1$ & \\
\hline & 30 & $50.9 \pm 0.05$ & \\
\hline & 15 & $38.2 \pm 0.05$ & \\
\hline
\end{tabular}

Table 6. \%age inhibition of extract / fraction against fungal agents

\begin{tabular}{|l|l|l|l|}
\multirow{2}{*}{ Extract/Fractions } & \multicolumn{3}{l}{ Percentage of inhibitions (\%) } \\
\cline { 2 - 4 } & Rhizoctoniasolani & Alternaria alternate & Fusariumoxysporum \\
\hline n-hexane fraction & $40 \pm 0.94$ & $25 \pm 0.81$ & $12 \pm 0.67$ \\
\hline Methanolic extract & 0 & $20 \pm 0.58$ & 0 \\
\hline
\end{tabular}

Table 7. Antibacterial activity of methanolic extract and n-hexane fraction

\begin{tabular}{|c|c|c|c|}
\hline Bacterial species & Methanolic extract & n-hexane fraction & Novobiocin \\
\hline B.Subtilus & $14 \pm 0.18$ & $12 \pm 0.18$ & $18 \pm 0.18$ \\
\hline S.aureus & $18 \pm 0.19$ & $13 \pm 0.21$ & $22 \pm 0.11$ \\
\hline
\end{tabular}


Table 8. MIC determination of methanolic extract and $n$-hexane fraction for antibacterial activity

\begin{tabular}{|c|c|c|c|}
\hline Extracts and Fractions & Concentration $(\mu \mathrm{g} / \mathrm{L})$ & S. aureus & B. subtilis \\
\hline \multirow{4}{*}{ Methanolic extract } & 0.1 & 0 & 0 \\
\cline { 2 - 4 } & 0.12 & 8 & 0 \\
\cline { 2 - 4 } & 0.14 & 11 & 7.5 \\
\cline { 2 - 4 } & 0.16 & 12.5 & 8 \\
\cline { 2 - 4 } & 0.18 & 16 & 0 \\
\cline { 2 - 4 } & 0.1 & 0 & 7 \\
\cline { 2 - 4 } n-hexane fraction & 0.12 & 0 & 8.5 \\
\cline { 2 - 4 } & 0.14 & 7 & 11 \\
\cline { 2 - 4 } & 0.16 & 7.7 & 12 \\
\hline
\end{tabular}

0
0
0
0
00
00
0
0
0
0
00
0
0
0
0
0
0
0

\section{$\mathrm{IC}_{50}$ Values of Fractions and Standard}

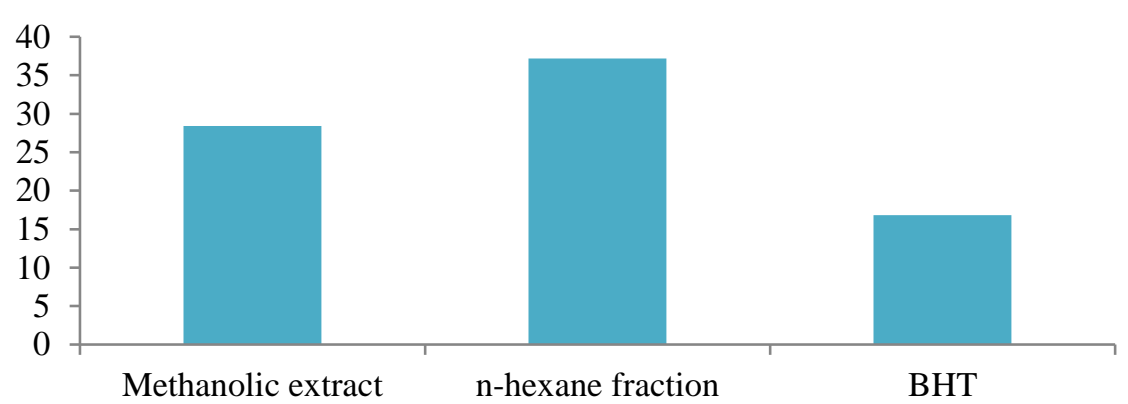

Figure 7. Comparison of scavenging activity of n-hexane fraction, methanolic extract and BHT standard

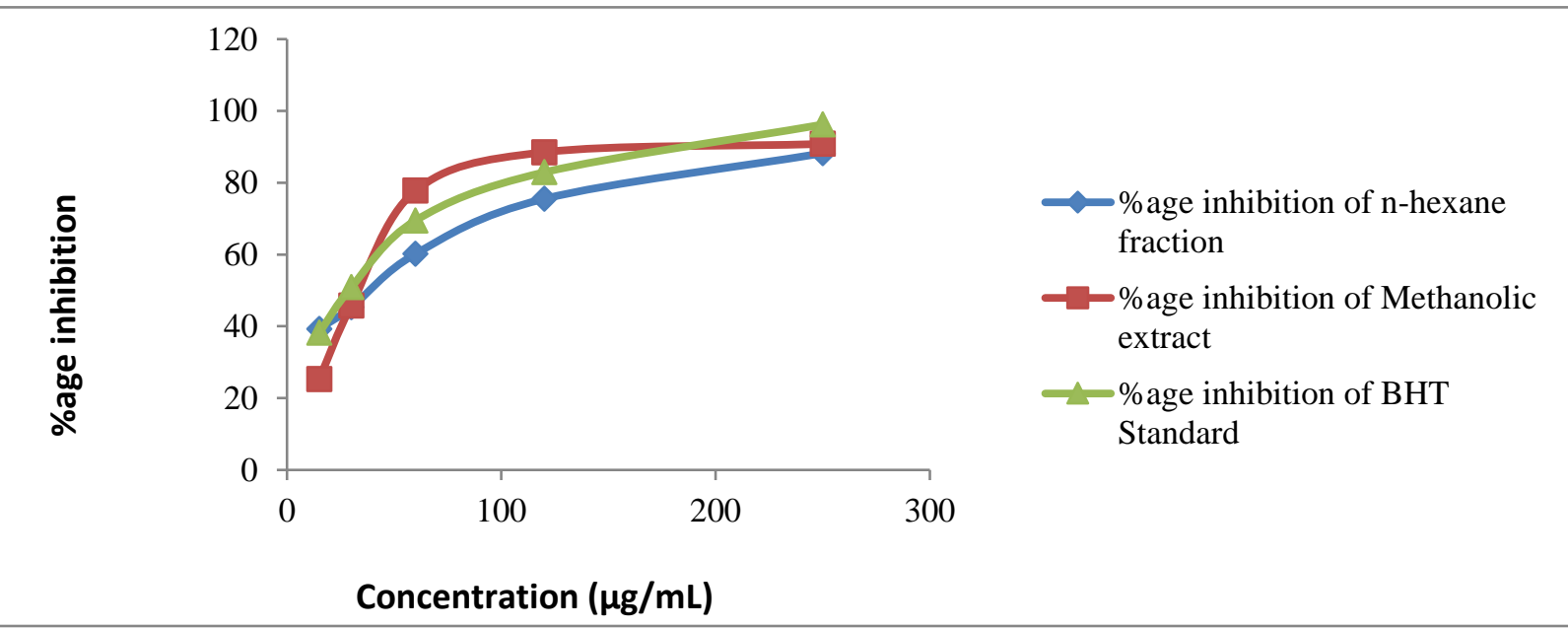

Figure 8. Scavenging activity at different dilutions 


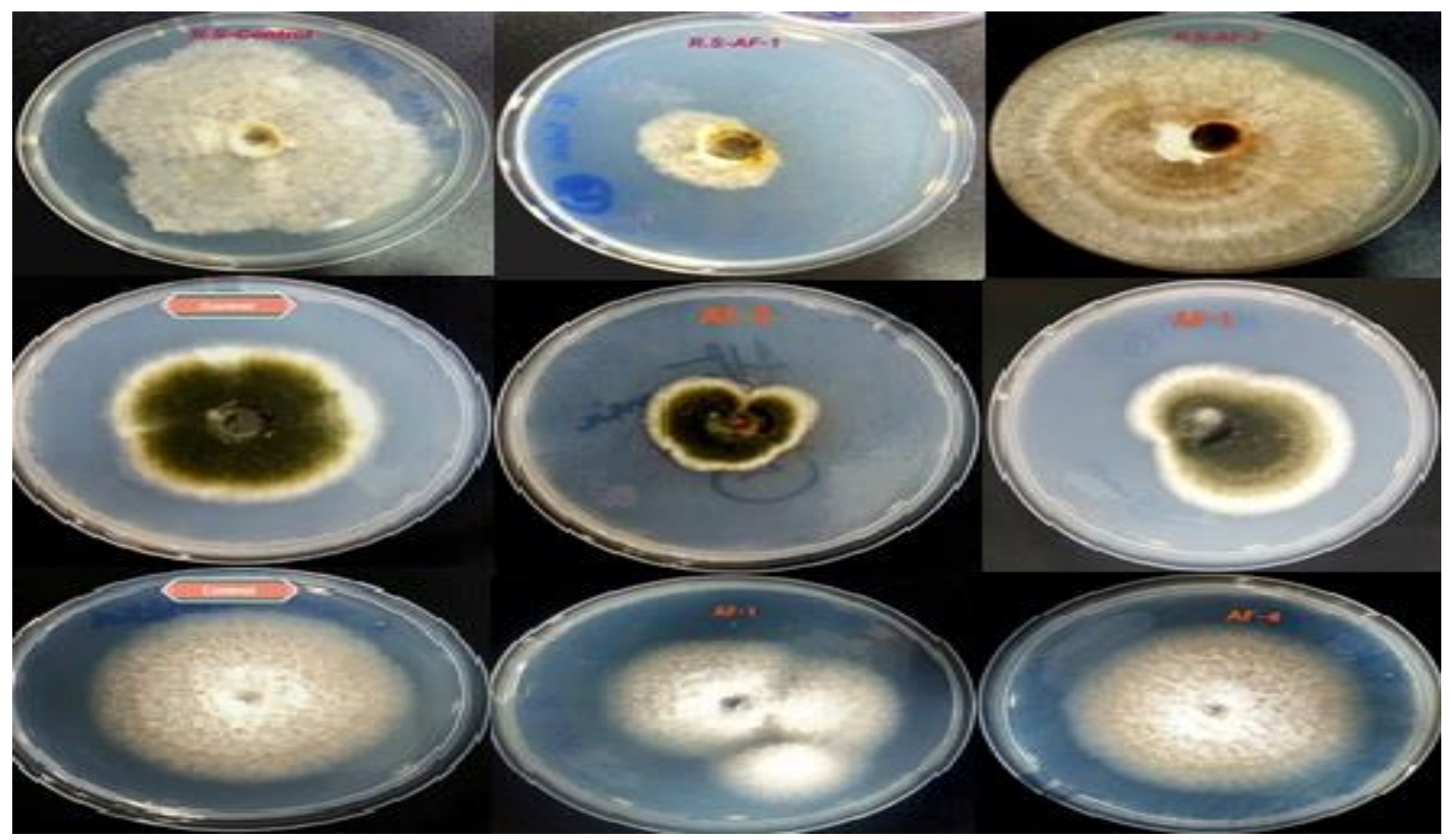

Figure 9. Petri plates showing inhibition zones of fractions against fungal strains

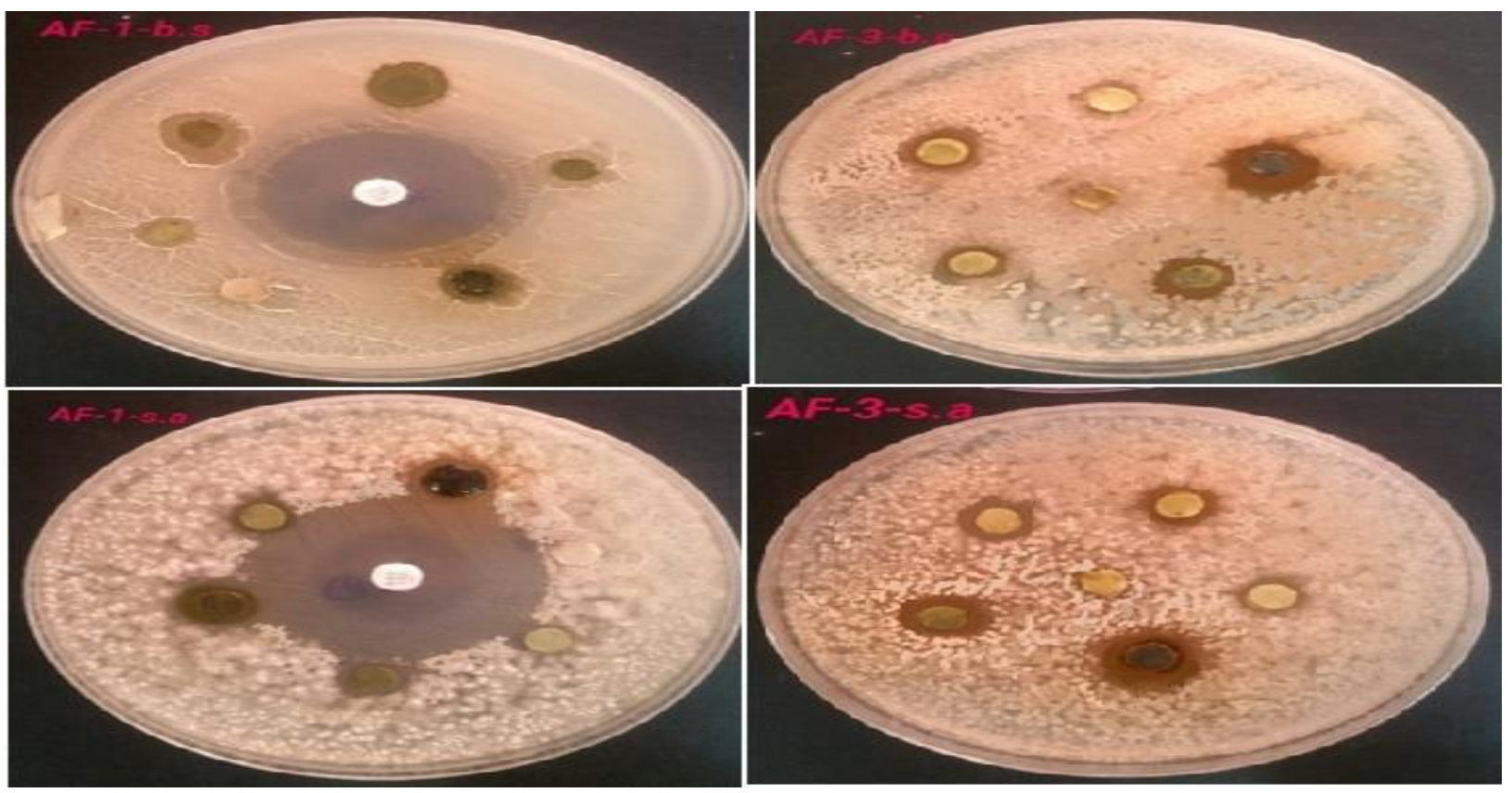

Figure 10. Petri plates showing inhibition zones of fractions against antibacterial strains against

\section{Conclusion}

The present work concluded that Phlomis stewartii is one of the important medicinal plants. The GC-MS analysis of n-hexane fraction revealed the presence of long chain acids, esters, stigmasterol, polyphenols and 
other sterols. The qualitative and quantitative screening confirmed the presence of flavonoids, saponins and total phenolic contents in methanolic extract and n-hexane fraction. The presence of these phytochemicals can be reason behind the biological activities. The methanolic extract showed the more antioxidant potential, it may be due to combined effect of many compounds such sterols, particularly esters have the potential of scavenging free radicals. n-hexane fraction showed significant antibacterial activity. The presence of long chain fatty acids including eicosanoic acid and linoleic acid etc. are potent agent for antibacterial activity. n-hexane fraction also exhibited the higher antifungal activity. The Phlomis stewartii is a potential plant which may further be explored and studied for the bioassay guided isolation of pure compounds.

\section{Author's contributions}

Conceived and designed the experiments: $S$ Ali, Performed the experiments: A Farooq, Analyzed the data: S Ali \& H Ullah, Contributed reagents/materials/ analysis tools: A Khan, N Jahan, I Agha \& RB Tareen, Wrote the paper: A Farooq \& S Ali.

\section{Acknowledgement}

The authors warmly acknowledge Department of Chemistry, University of Balochistan, Quetta and Faculty of Life Sciences and Informatics, BUITEMS, Quetta for providing the necessary equipments and labs in order to conduct lab work smoothly.

\section{References}

1. Cooper R \& Nicolo G (2014). Natural Products Chemistry: Sources, Separations and Structures. $1^{\text {st }}$ Ed. CRC Press, Taylor \& Francis group, pp206.

2. Abozenadah, Bishop H, Bittner \& Flatt (2018). Allied Health Chemistry. $1^{\text {st }}$ Ed. Western Oregon University, Oregon State (America), pp 208.

3. Dhawan D \& Gupta J (2017). Comparison of different solvents for
Phytochemical extraction potential from Datura metel plant leaves. Intl J Biol Chem 11 (1): 17-22.

4. Koche D, Shirsat R \& Kawale M (2016). An overview of major classes of Phytochemicals: their types and role in disease prevention. Hislopia J 9(1/2): 111.

5. Donmez AA (2003). Iridoid and Phenylpropanoid Glycosides from Phlomis samia, P. monocephala and $P$. carica. Turk J Chem 27: 295-305.

6. Paiva, SA, and RM Russell (1999). BetaCarotene and Other Carotenoids as Antioxidants. J Am Coll Nutr 18(5): 426-433.

7. Cheij I (1984). Studies on bark of Morus species used to relieve tooth ache and other medicinal purpose. The Macdonald Encyclopedia of Medicinal Plants. Macdonald \& Co (Publishers) Ltd, pp 365.

8. Jabeen B, Riaz N, Saleem M, Naveed MA, Ashraf M, Alam U, Rafiq HM, Tareen RB \& Jabbar A (2013). Isolation of Natural Compounds from Phlomis stewartii showing $\alpha$-hlucosidase inhibitory activity, Phytochem 96: 443448.

9. Sarker S \& Nahar L (2007). Chemistry for Pharmacy Students: General Organic and Natural Product Chemistry. John Wiley \& Sons, pp 283.

10. Mensor LL, Menezes FS, Leitao GG, Reis AS, Santos TCS, Coube CS \& Leitao SG (2001).Screening of Brazilian plant extracts for antioxidant activity by using DPPH free radical method. Phytother Res 15: 127-130.

11. Hussain SZ \& Maqbool K (2014). GCMS principle, technique and its application in food science. Intl J Curr Sci 13: 116-126.

12. Stein SE (2008). NIST Standard Reference Database 1A. Gaithersburg 2: 975-980. 
13. Mir MA, Sawhney SS \& Jassal MMS (2012). Qualitative and quantitative analysis of phytochemicals of Taraxacum officinale. $J$ Pharm Pharmacol 2(1): 1-5.

14. Saxena M, Saxena J, Nema R, Singh D \& Gupta A (2013). Phytochemistry of medicinal plants. $J$ Pharmacogn Phytochem 1(6): 168-182.

15. Koleva II, Beek TAV, Linssen JPH, Groot AD \& Evstatieva LN (2002). Screening of Plant Extracts for Antioxidant Activity: A Comparative Study on three testing methods. Phytochem Anal 13: 8-17.

16. Semnani KM, Saeedi M, Mahdavi MR \& Rahimi F (2006). Antimicrobial studies on extracts of three species of Phlomis. Pharm Biol 44(6): 426-429.

17. Smania EDFA, DelleMonache F, Yunes, RA, Paulert R, \& Smania Junior A (2007). Antimicrobial activity of methyl australate from Ganoderma australe. Rev Bras Farmacogn 17(1): 14-16.

18. Ozkan G, Sagdic O, Baydar NG \& Baydar H (2004). Note: Antioxidant and antibacterial activities of Rosa damascena flower extracts. Food Sci Tech Int 10(4): 277-281.

19. Achuthan CR, Babu BH \& Padikkhala J (2003). Antioxidant and hepatoprotective effects of Rosa damascena. Pharm Biol 41(5): 357-361.

20. Harput US, Saracoglu I, Calis I, Donmez AA \& Nagatsu A (2004). Secondary metabolites from Phlomis kotschyana. Turk J Chem 28: 767-774.

21. Shang X, Wang J, Li M, Miao X, Pan H, Yang Y \& Wang Y (2011). Antinociceptive and anti-inflammatory activities of Phlomis umbrosa Turcz extract. Fitoterapia 82: 716-721.
22. Tsitsimi E, Loukis A \&Verykokidou E (2011). Composition of the Essential Oil of the Flowers of Phlomis fruticosa L. from Greece. J Essent Oil Res 12(3): 355-356.

23. Zhang Y \& Wang ZZ (2008). Comparative analysis of essential oil components of three Phlomis species in Qinling Mountains of China. J Pharm Biomed Anal 47: 213-217.

24. Shayan SZ, Moradkhani S \& Dastan D (2016). Analysis of fatty acid composition of two selected Phlomis species. J HerbMed Pharmacol 5(4): 153-156.

25. Lofty RA \& Abd El-Moaty HI (2016). Antibacterial activities of some active constituents isolated from Phlomis Floccosa D. Don. Egypt J Desert Res 66 (1): 69-78.

26. Nazemiyeh H, Rahman MM, Gibbons S, Nahar L, Delazar A, Ghahramani MA, Talebpour AH, \& Sarker SD (2008). Assessment of antibacterial activity of phenylethanoid glycosides from Phlomis lanceolata against multidrug resistant strains of Staphylococcus aureus. J Nat Med 62: 91-95.

27. Shtayen MSA \& Ghdeib SIA (1999). Antifungal activity of plant extract against dermatophytes. Mycoses, 42:665-672.

28. Hammer KA, Carson CF \& Riley TV (1999). Antimicrobial activity of essential oils and other plant extracts. $J$ Appl Microbiol 86: 985-990.

29. Dellavalle PD, Cabrera A, Alem D, Larranaga P, Ferriera F \& Rizza MD (2011). Antifungal activity of medicinal plant extracts against Phytopathogenic fungus Alternaria spp. Chil J Agr Res 71(2): 231-239. 